\title{
Microrganismos produtores de hidrolases envolvidos nas transformações dos compostos do carbono e do nitrogênio do solo
}

\author{
Hydrolases producers microorganisms involved in the soil carbon and nitrogen cycling
}

\author{
Luciana Terumi Sanomiya $^{1}$ Ely Nahas $^{2}$
}

RESUMO

Avaliou-se o efeito de culturas de braquiária $e$ guandu, da adubação fosfatada e da calagem sobre bactérias e fungos amilolíticos, celulolíticos, proteolíticos e ureoliticos. A proporção das bactérias com atividade enzimática em relação ao total variou de 25 a $87 \%$ e, a dos fungos, de 2 a 36\%. Os grupos de bactérias aumentaram sua população nas parcelas em que se aplicou superfosfato e calcário em relação aos outros tratamentos (exceto as ureoliticas que aumentaram na ausência de adubo) e os fungos prevaleceram na ausência de adubação (exceto os ureoliticos que aumentaram com superfosfato) e de calagem. No solo cultivado com braquiária, foram obtidas as maiores contagens de bactérias ureoliticas e fungos proteolíticos. Na ausência de planta, preponderaram os fungos CM-celuloliticos (CM, celulose microcristalina) e ureolíticos e na presença de guandu, os amiloliticos e CMC-celulolíticos (CMC, carboximetilcelulose). Os demais grupos de bactérias não foram influenciados pelo sistema de cultivo. A população e a habilidade enzimática dos fungos foram menores que as das bactérias, o que sugere menor participação na transformação dos nutrientes no solo. As bactérias apresentaram múltiplas atividades enzimáticas, mostrando maior versatilidade que os fungos.

Palavras-chave: bactérias, fungos, amiloliticos, celuloliticos, proteoliticos, ureoliticos, fósforo, braquiária, guandu.

\section{ABSTRACT}

The effect of plant cultures, Brachiaria ruziziensis, Cajanus cajan, of the phosphate fertilizers and of the liming on amilolytic, cellulolytic, proteolytic and ureolytic bacteria and fungi were investigated. The proportion of bacteria with enzymatic activity in relation to the total varied from 25 to $87 \%$ and fungi from 2 to $36 \%$. The groups of bacteria increased its population in plots added with superphosphate and lime in relation to the other treatments (except the ureolytic that increased in plots not fertilized) and the fungi enhanced in the unfertilized (except the ureolytics that increased with superphosphate) and limed plots. The highest counts of ureolytic bacteria and proteolytic fungi were found in the soil cultivated with B. ruziziensis. The CM-cellulolytic (CM, cellulose microcrystalline) and ureolytic fungi enhanced in the uncultivated plots and the amilolytic and CMC-cellulolytic (CMC, carboxymethylcellulose) in the plots cultivated with $C$. cajan. The other groups of bacteria were not influenced by the cultivation system. The population and the enzymatic ability of the fungi groups were smaller than the bacteria, suggesting a smaller participation in the nutrients cycling in the soil. The bacteria presented multiple enzymatic activities, showing larger versatility than the fungi.

Key words: bacteria, fungi, amilolytic, cellulolytic, proteolytic, ureolytic, phosphorus, Brachiaria ruziziensis, Cajanus cajan.

\section{INTRODUÇÃO}

O processo de mineralização da matéria orgânica é catalisado por diferentes enzimas, produzidas na sua maioria pelos microrganismos do solo (AOKI et al., 1995), cuja importância estaria relacionada à possibilidade de pressupor as reações de decomposição que poderão ocorrer no solo e a disponibilidade de compostos importantes para a

${ }^{1}$ Bióloga, MSc em Microbiologia, Doutoranda do Programa de Pós-graduação em Microbiologia, Universidade Estadual Paulista (UNESP), Jaboticabal.

${ }^{2}$ Engenheiro Agrônomo, Professor Titular, Departamento de Produção Vegetal, FCAV, UNESP Jaboticabal. Rod. Prof. Paulo Donato Castellane, km 5, 14884-000, Jaboticabal- SP. E-mail: enahas@fcav.unesp.br. Autor para correspondência 
nutrição das plantas (TIWARI et al., 1988). Na degradação de celulose, por exemplo, as reações envolvidas tornam o carbono disponível para o crescimento de microrganismos (DENG \& TABATABAI, 1994).

Foi verificado que $65 \%$ dos isolados microbianos de solos ácidos foram proteolíticos, e destes, $12 \%$ com alta atividade (TSHERING \& PAUL, 1988). WATANABE (1997) observou que solos sob diferentes condições podem causar variações na população bacteriana proteolítica. Dos isolados obtidos em diferentes solos cultivados e não cultivados, 68 linhagens apresentaram atividade proteolítica (NISKANEN \& EKLUND, 1986). Da mesma forma, a aplicação de resíduos orgânicos aumentou tanto a atividade de urease como o número de microrganismos ureolíticos (SLIZAK \& STEFANIAK, 1990) e proteolíticos (DEVLIEGHER \& VERSTRAETE, 1995).

Vários estudos sobre o efeito de culturas e da aplicação de fertilizantes sobre os microrganismos têm sido conduzidos. Neste sentido, foi observado que o número de bactérias aumentou em solo cultivado com aveia ou adubado com superfosfato em relação ao controle (sem fósforo) (LOUW \& WEBLEY, 1959). A freqüência de populações de bactérias com atividade enzimática encontrada em solos com diferentes plantas ocorreu na seguinte ordem decrescente: proteolíticas $>$ lipolíticas $>$ amilolíticas $>$ pectolíticas $>$ celulolíticas (HANKIN et al., 1974). A calagem de área sob pastagem propiciou um aumento da população total de bactérias e de Gram negativas e bem como do carbono da biomassa microbiana, entretanto a mineralização do $\mathrm{N}$ orgânico não foi afetada (SARATHCHANDRA \& UPSDELL, 1981). SALAMA et al.. (1992) verificaram que apenas em baixas aplicações de uréia ao solo ocorreu aumento da população fúngica e dos níveis de amonificação e nitrificação.

Considerando que inúmeros fatores de natureza biológica ou físico-química podem influir no número e atividade enzimática dos microrganismos do solo, este trabalho avaliou o efeito da adubação fosfatada, de diferentes culturas e bem como da calagem sobre o número de microrganismos com atividade amilolítica, celulolítica, proteolítica e ureolítica de um Latossolo Vermelho distrófico.

\section{MATERIAL E MÉTODOS}

O ensaio foi conduzido em Latossolo Vermelho distrófico na Fazenda Boa Esperança de Minas, em Comendador Gomes, MG, descrito por BARROTI \& NAHAS (2000), apresentando: M.O =
$1,5 \mathrm{~g} \mathrm{~kg}^{-1} ; \mathrm{P}=4 \mathrm{mg} \mathrm{dm}{ }^{-3} ; \mathrm{pH} \mathrm{em} \mathrm{CaCl}_{2}=4,5$; cátions trocáveis expressos em mmoles $\mathrm{dm}^{-3}: \mathrm{Ca}=0,9 ; \mathrm{Mg}=$ 0,$4 ; \mathrm{K}=0,05$ e $\mathrm{Al}=0,18$.

Foi utilizado experimento fatorial $3 \times 3 \times 2$, cujos fatores foram: plantas (controle, braquiária, Brachiaria ruziziensis, e guandu, Cajanus cajan), fertilizantes (controle, superfosfato simples com 18\% de $\mathrm{P}_{2} \mathrm{O}_{5}$ e apatita de Araxá com $18,5 \%$ de $\mathrm{P}_{2} \mathrm{O}_{5}$, na dose de $400 \mathrm{~kg} \mathrm{P}_{2} \mathrm{O}_{5}$ ha $^{-1}$, incorporados ao solo) e calagem (com e sem calcário). A comparação de médias foi feita pelo teste de Tukey ao nível de significância de $\mathrm{P}<0,05$.

De cada parcela, foram retiradas 10 amostras na profundidade de $0-20 \mathrm{~cm}$. Após a retirada de material estranho e homogeneização, o solo foi acondicionado sob refrigeração. Foi utilizado o meio de BUNT \& ROVIRA (1955), para contagem de bactérias totais, e o meio de MARTIN (1950), para contagem de fungos, utilizando-se diluições sucessivas de $10^{-1}$ a $10^{-8}$ das amostras de solo de $10 \mathrm{~g}$. As placas (4 por diluição) foram incubadas à temperatura de $30^{\circ} \mathrm{C}$ por 24h (bactérias) e $72 \mathrm{~h}$ (fungos). As bactérias (50 por tratamento) e os fungos ( 40 por tratamento) foram isolados com base nas características morfológicas das colônias (BUYER \& KAUFMAN, 1996) em meio BDYA (batata, dextrose, extrato de levedura e ágar) (KUCEY, 1983).

A atividade celulolítica dos isolados foi avaliada pelo método de HENDRICKS et al. (1995), utilizando-se como substratos a celulose microcristalina (CM) e a carboximetilcelulose (CMC). Para as atividades amilolítica, proteolítica e ureolítica, empregaram-se os procedimentos de MELO \& CAMPOS-TAKAKI (1989), CAPLAN \& FAHEY (1982) e CHRISTENSEN (1946), respectivamente.

A habilidade enzimática de cada isolado foi medida através da relação entre o diâmetro do halo de atividade e o diâmetro da colônia e os resultados foram agrupados por faixa de atividade. Para identificação da atividade enzimática e medida dos halos de atividade, os isolados foram inoculados nos meios de cultura e incubados à temperatura de $30^{\circ} \mathrm{C}$ por 72 horas para as bactérias e 120 horas para os fungos. A atividade amilolítica foi detectada pela formação de um halo amarelo ao redor da colônia, após adição do reagente de iodo ao meio. As atividades celulolítica e proteolítica foram evidenciadas pela formação de halo incolor ao redor da colônia resultante da degradação do substrato, que foi melhor visualizado embebendose as placas com $\mathrm{HCl} 0,5 \mathrm{M}$ por 15 minutos. A atividade dos microrganismos produtores de urease foi constatada pela formação de halo rosado em decorrência da mudança de $\mathrm{pH}$ do indicador vermelho 
de fenol. Os diâmetros das colônias e dos halos foram medidos com uma régua em milímetros.

\section{RESULTADOS E DISCUSSÃO}

A tabela 1 mostra que o número de bactérias ureolíticas variou de 0,69 a 4,41 x $10^{6} \mathrm{UFC} \mathrm{g}^{-1}$ solo seco com uma média de $1,96 \times 10^{6} \mathrm{UFC}^{-1}$ solo seco, correspondendo a $25,1 \%$ do número total de bactérias. A proporção dos demais grupos bacterianos foi de
$86,8 \%$ para as bactérias CMC-celulolíticas, $78,7 \%$ para as CM-celulolíticas, $69,9 \%$ para as proteolíticas e $26,6 \%$ para as amilolíticas. Houve aumento significativo $(\mathrm{P}<$ 0,05 ) de 8,8 a $38,9 \%$ (média de $18,9 \%$ ) das populações de bactérias estudadas por efeito da calagem, exceto as CM-celulolíticas e as proteolíticas.

A variação do número das bactérias amilolíticas, de 0,60 a 4,36 x $10^{6} \mathrm{UFC} \mathrm{g}^{-1}$ solo seco, foi semelhante à encontrada por NEAL et al. (1973) em solo não rizosférico. Todos os fatores estudados bem

Tabela 1 - Populações de bactérias envolvidas nas transformações dos compostos do carbono e do nitrogênio de solo submetido a diferentes manejos ou sistemas de cultivo

\begin{tabular}{|c|c|c|c|c|c|c|}
\hline \multirow{2}{*}{ TRATAMENTOS } & Totais & Amilolíticas & CM-celulolíticas & $\begin{array}{c}\text { CMC- } \\
\text { celulolíticas }\end{array}$ & Proteolíticas & Ureolíticas \\
\hline & \multicolumn{6}{|c|}{ UFC $\times 10^{6} \mathrm{~g}^{-1}$ solo seco } \\
\hline \multicolumn{7}{|l|}{ Sem Calagem } \\
\hline \multicolumn{7}{|l|}{ Sem Adubo } \\
\hline Sem Planta & 6,94 & 2,08 & 6,94 & 6,25 & 6,11 & 1,25 \\
\hline Brachiária & 7,53 & 0,60 & 4,97 & 5,87 & 4,97 & 3,31 \\
\hline Guandu & 6,39 & 1,28 & 5,11 & 5,75 & 4,85 & 1,79 \\
\hline \multicolumn{7}{|l|}{ Superfosfato } \\
\hline Sem Planta & 6,00 & 2,52 & 5,64 & 5,40 & 4,56 & 2,40 \\
\hline Brachiária & 9,09 & 2,91 & 6,55 & 8,19 & 6,73 & 1,64 \\
\hline Guandu & 7,77 & 1,24 & 5,90 & 6,21 & 5,75 & 1,40 \\
\hline \multicolumn{7}{|l|}{ Fosfato de Rocha } \\
\hline Sem Planta & 6,70 & 1,47 & 6,16 & 6,03 & 4,96 & 2,41 \\
\hline Brachiária & 7,41 & 3,71 & 5,63 & 5,93 & 5,32 & 2,52 \\
\hline Guandu & 6,70 & 1,34 & 6,03 & 5,49 & 4,55 & 0,80 \\
\hline \multicolumn{7}{|l|}{ Com Calagem } \\
\hline \multicolumn{7}{|l|}{ Sem Adubo } \\
\hline Sem Planta & 9,19 & 3,86 & 8,64 & 8,82 & 4,60 & 4,41 \\
\hline Brachiária & 9,66 & 2,51 & 8,30 & 8,69 & 7,14 & 4,06 \\
\hline Guandu & 6,96 & 1,53 & 6,54 & 6,12 & 5,29 & 1,95 \\
\hline \multicolumn{7}{|l|}{ Superfosfato } \\
\hline Sem Planta & 11,65 & 3,50 & 9,09 & 11,18 & 8,16 & 1,86 \\
\hline Brachiária & 11,50 & 4,36 & 7,80 & 10,09 & 7,34 & 2,75 \\
\hline Guandu & 8,64 & 3,98 & 7,43 & 6,74 & 5,71 & 0,69 \\
\hline \multicolumn{7}{|l|}{ Fosfato de Rocha } \\
\hline Sem Planta & 8,06 & 2,42 & 5,65 & 7,90 & 6,94 & 2,10 \\
\hline Brachiária & 7,06 & 0,71 & 3,11 & 5,65 & 3,96 & 1,98 \\
\hline Guandu & 7,38 & 3,84 & 5,46 & 6,06 & 4,43 & 2,22 \\
\hline \multicolumn{7}{|l|}{ Teste F } \\
\hline Planta (A) & $1,94^{\mathrm{NS}}$ & $6,91^{* *}$ & $2,42^{\mathrm{NS}}$ & $3,32^{\mathrm{NS}}$ & $1,54^{\mathrm{NS}}$ & $33,32 * *$ \\
\hline Adubo (B) & $3,17^{\mathrm{NS}}$ & $21,69 * *$ & $6,47 * *$ & $3,59 *$ & $3,91 *$ & $13,24 * *$ \\
\hline Calagem (C) & $8,91 * *$ & $41,97 * *$ & $3,01^{\mathrm{NS}}$ & $11,89 * *$ & $1,79^{\mathrm{NS}}$ & $7,88^{*}$ \\
\hline$A \times B$ & $0,47^{\mathrm{NS}}$ & $10,04 * *$ & $1,57^{\mathrm{NS}}$ & $0,88^{\mathrm{NS}}$ & $1,12^{\mathrm{NS}}$ & $2,59^{\mathrm{NS}}$ \\
\hline $\mathrm{A} \times \mathrm{C}$ & $1,63^{\mathrm{NS}}$ & $9,88 * *$ & $0,55^{\mathrm{NS}}$ & $2,58^{\mathrm{NS}}$ & $0,78^{\mathrm{NS}}$ & $0,52^{\mathrm{NS}}$ \\
\hline $\mathrm{B} \times \mathrm{C}$ & $1,14^{\mathrm{NS}}$ & $12,57 * *$ & $7,71 * *$ & $0,99^{\mathrm{NS}}$ & $0,88^{\mathrm{NS}}$ & $7,89 * *$ \\
\hline $\mathrm{A} \times \mathrm{B} \times \mathrm{C}$ & $0,48^{\mathrm{NS}}$ & $26,35^{* *}$ & $1,32^{\mathrm{NS}}$ & $0,75^{\mathrm{NS}}$ & $3,27 *$ & $14,75^{* *}$ \\
\hline $\mathrm{CV}$ & 1,29 & 1,42 & 1,32 & 1,31 & 1,33 & 1,42 \\
\hline
\end{tabular}

Obs. NS, não significativo; *, significativo $(\mathrm{P}<0,05)$; **, significativo $(\mathrm{P}<0,01)$.

Ciência Rural, v. 33, n. 5, set-out, 2003. 
como suas interações influíram nos números de bactérias amilolíticas. Analisando-se os fatores isoladamente, verifica-se que o número de bactérias amilolíticas aumentou nas parcelas não cultivadas (controle), nas adubadas com superfosfato e nas que se efetuou a calagem. Entretanto, quando se considerou a interação planta-adubo, a associação braquiáriasuperfosfato foi a que propiciou o maior aumento do número de bactérias amilolíticas $\left(2,91\right.$ e 4,36 x $10^{6}$ UFC $\mathrm{g}^{-1}$ solo seco) (Tabela 1).

As populações de bactérias CM e CMCcelulolíticas variaram, respectivamente, de 3,11 a 9,09 e 5,49 a $11,18 \times 10^{6} \mathrm{UFC} \mathrm{g}^{-1}$ solo seco. Estes números comparam-se aos obtidos por LINHARES \& DROZDOWICZ (1972). VARDAVAKIS (1989) encontrou populações variáveis de zero a $13 \times 10^{6} \mathrm{~g}^{-1}$ solo seco, dependendo da estação do ano e da profundidade da amostragem, concluindo que outros fatores podem influir na contagens dos celulolíticos. Embora a população bacteriana total encontrada por NEAL et al. (1973) tenha sido maior, a proporção de bactérias com atividade celulolítica e amilolítica foi bem menor que a encontrada neste trabalho.

$\mathrm{O}$ crescimento das bactérias CMcelulolíticas foi influenciado pela adubação e pela interação adubo x calagem, e as bactérias CMCcelulolíticas apenas pelos fatores estudados isoladamente, exceto pela planta, e não pelas respectivas interações (Tabela 1). As contagens das bactérias CM e CMC-celulolíticas foram maiores nos tratamentos com superfosfato ou sem adubação que nas adubadas com fosfato de rocha. Essas respostas foram mais significativas na presença de calagem (Tukey, $\mathrm{P}<0,05$ ).

Os números de bactérias proteolíticas $(3,96$ a $8,16 \times 10^{6} \mathrm{UFC} \mathrm{g}^{-1}$ solo seco) comparam-se com os obtidos por HANKIN et al. (1974), contudo foram inferiores aos encontrados por WATANABE et al. (1994) que verificaram uma variação de 5,4 a 23,9 x $10^{6}$ UFC $\mathrm{g}^{-1}$ solo seco. As porcentagens de bactérias proteolíticas em relação ao total variaram de 9,2 a 15,7\% (WATANABE \& HAYANO, 1995) e de 16,7 a $30,0 \%$ (SUYAMA et al., 1993), portanto, bem inferiores às obtidas neste trabalho.

A população de bactérias ureolíticas aumentou na ausência de adubo e na presença de braquiária. A influência do cultivo de plantas também foi obtida por BADALUCCO et al. (1996) que verificaram significativo aumento do número de bactérias totais na presença do que na ausência de plantas. Segundo LLOYD \& SHEAFFE (1973), as bactérias ureolíticas respondem a uma fonte de carbono representada pela glicose. Poderia se admitir que esse aumento fosse influenciado por algum fator inerente ao cultivo de braquiária, contudo essas bactérias foram também favorecidas nas parcelas não cultivadas. Esses autores verificaram proporções de 20 a $40 \%$ do total à semelhança dos resultados encontrados neste trabalho.

As bactérias proteolíticas, de modo diferente às ureolíticas, não foram influenciadas pelo fator planta e aumentaram pela aplicação de superfosfato. Em acordo com os resultados obtidos neste trabalho, a adubação parece ser um fator essencial para o incremento das bactérias proteolíticas como foi verificado por WATANABE \& HAYANO (1995) que constataram aumento do número de bactérias proteolíticas de 0,8 a $6,5 \%$ pela adição de fertilizantes químicos em relação ao controle.

A população de fungos que apresentam atividade das enzimas estudadas (Tabela 2) foi bem menor que a das bactérias, o que sugere menor participação no processo de transformação dos nutrientes no solo. A menor média encontrada foi a dos fungos amilolíticos, de 2,46 x $10^{3} \mathrm{UFC} \mathrm{g}^{-1}$ solo seco, e correspondeu a $2,0 \%$ do total de fungos. A proporção dos CM-celulolíticos foi de 36,3\%, dos CMCcelulolíticos de $35,9 \%$, dos ureolíticos de $11,7 \%$ e dos proteolíticos de 2,3\%.

Excetuando-se o efeito da calagem nas contagens dos fungos CMC-celulolíticos, todos os fatores analisados e suas respectivas interações foram significativos. A população de fungos aumentou na ausência de adubação ou de calagem. Ausência de resposta à adubação fosfatada da população de fungos totais foi encontrada também por LIMA et al. (1996). A freqüência de fungos diminuiu por efeito da calagem de 7,5 a $47,0 \%$ (média de $26,8 \%$ ) o que sugere que este grupo é menos sensível ao aumento do $\mathrm{pH}$ que as bactérias. Na ausência de planta, prevaleceram os fungos CM-celulolíticos e ureolíticos; nas parcelas cultivadas com braquiária predominaram os proteolíticos e, nas de guandu, os amilolíticos e CMCcelulolíticos (Tabela 2).

Analisando-se as interações entre os tratamentos (Tabela 2), constata-se que na ausência de calagem as maiores contagens de amilolíticos $(1,24-$ $1,45 \times 10^{4} \mathrm{UFC} \mathrm{g}^{-1}$ solo seco), CM-celulolíticos $(8,24-$ $8,64 \times 10^{4} \mathrm{UFC} \mathrm{g}^{-1}$ solo seco) e ureolíticos $(1,23-3,88$ $\mathrm{x} 10^{4} \mathrm{UFC} \mathrm{g}^{-1}$ solo seco) foram obtidas na ausência de planta tanto nas parcelas não adubadas como nas adubadas com fosfato de rocha. A população dos CMCcelulolíticos aumentou em relação ao controle, quando se associou o cultivo de braquiária à adubação fosfatada. Apenas com a aplicação de formulação completa de adubos em latossolo roxo ou latossolo vermelho escuro aumentou-se o número de celulolíticos acima do controle (DANTAS \& DROZDOWICZ, 1972). A 
Tabela 2 - Populações de fungos envolvidas nas transformações dos compostos do carbono e do nitrogênio de solo submetido a diferentes manejos ou sistemas de cultivo

\begin{tabular}{ccc}
\hline TRATAMENTOS Totais Amilolíticos & CM-celulolíticos & $\begin{array}{l}\text { CMC- } \\
\text { celulolíticos }\end{array}$ \\
UFC x $10^{4} \mathrm{~g}^{-1}$ solo seco
\end{tabular}

\begin{tabular}{|c|c|c|c|c|c|c|}
\hline \multicolumn{7}{|l|}{ Sem Calagem } \\
\hline \multicolumn{7}{|l|}{ Sem Adubo } \\
\hline Sem Planta & 14,40 & 1,24 & 8,64 & 4,53 & 0,82 & 1,23 \\
\hline Brachiária & 10,24 & 0,33 & 2,17 & 4,63 & 1,51 & 1,24 \\
\hline Guandu & 10,66 & 0,58 & 4,61 & 4,32 & 0,86 & 1,44 \\
\hline \multicolumn{7}{|l|}{ Superfosfato } \\
\hline Sem Planta & 9,11 & 0,25 & 4,19 & 2,22 & 1,23 & 1,72 \\
\hline Brachiária & 17,55 & 1,03 & 5,36 & 6,19 & 0,49 & 1,46 \\
\hline Guandu & 12,03 & 0,69 & 5,16 & 4,47 & 1,03 & 1,72 \\
\hline \multicolumn{7}{|c|}{ Fosfato de Rocha } \\
\hline Sem Planta & 14,05 & 1,45 & 8,24 & 3,39 & ND & 3,88 \\
\hline Brachiária & 9,36 & ND & 4,53 & 5,44 & 0,30 & 1,81 \\
\hline Guandu & 12,14 & 1,07 & 5,00 & 5,15 & 1,43 & 1,07 \\
\hline \multicolumn{7}{|c|}{ Com Calagem } \\
\hline \multicolumn{7}{|l|}{ Sem Adubo } \\
\hline Sem Planta & 20,36 & 1,27 & 12,21 & 11,45 & 0,58 & 4,65 \\
\hline Brachiária & 9,42 & 0,57 & 3,24 & 5,00 & 1,18 & 0,29 \\
\hline Guandu & 14,11 & 1,21 & 4,56 & 4,98 & 2,08 & 1,66 \\
\hline \multicolumn{7}{|l|}{ Superfosfato } \\
\hline Sem Planta & 14,67 & ND & 7,13 & 7,55 & 2,52 & 1,68 \\
\hline Brachiária & 19,04 & ND & 5,36 & 4,91 & 0,59 & 1,79 \\
\hline Guandu & 12,32 & 0,77 & 3,46 & 4,24 & ND & 1,54 \\
\hline \multicolumn{7}{|c|}{ Fosfato de Rocha } \\
\hline Sem Planta & 9,27 & 0,56 & 2,03 & 1,40 & 0,87 & 0,58 \\
\hline Brachiária & 10,12 & 0,29 & 2,40 & 2,89 & 0,53 & 1,07 \\
\hline Guandu & 15,17 & 1,99 & 3,59 & 6,39 & ND & 2,40 \\
\hline \multicolumn{7}{|l|}{ Teste F } \\
\hline Planta (A) & $1,44^{\mathrm{NS}}$ & $896,62 * *$ & $37,82 * *$ & $4,95^{*}$ & $311,91 * *$ & $35,77 * *$ \\
\hline Adubo (B) & $2,99^{\mathrm{NS}}$ & $679,28 * *$ & $9,99 * *$ & $18,61 * *$ & $744,66^{* *}$ & $5,36^{*}$ \\
\hline Calagem (C) & $3,82^{\mathrm{NS}}$ & $142,01 * *$ & $11,44 * *$ & $2,22^{\mathrm{NS}}$ & $128,96 * *$ & $11,93 * *$ \\
\hline$A \times B$ & $11,99 * *$ & $376,03 * *$ & $21,91 * *$ & $23,17 * *$ & $297,44 * *$ & $23,00 * *$ \\
\hline $\mathrm{A} \times \mathrm{C}$ & $0,66^{\mathrm{NS}}$ & $215,97^{* *}$ & $1,01^{* *}$ & $14,70^{* *}$ & $1296,14^{* *}$ & $22,26^{* *}$ \\
\hline $\mathrm{B} \times \mathrm{C}$ & $2,19^{\mathrm{NS}}$ & $1120,64^{* *}$ & $37,42 * *$ & $25,42 * *$ & $151,66^{* *}$ & $12,93 * *$ \\
\hline $\mathrm{A} \times \mathrm{B} \times \mathrm{C}$ & $4,53 *$ & $395,89 * *$ & $11,89 * *$ & $17,78 * *$ & $561,77 * *$ & $66,69 * *$ \\
\hline $\mathrm{CV}$ & 1,34 & 2,04 & 1,46 & 1,47 & 2,10 & 1,64 \\
\hline
\end{tabular}

Obs. NS, não significativo; *, significativo $(\mathrm{P}<0,05)$; **, significativo $(\mathrm{P}<0,01)$.

ND - Atividade Não Detectada

população de fungos proteolíticos $\left(1,51 \times 10^{4} \mathrm{UFC} \mathrm{g}^{-1}\right.$ solo seco) também aumentou nas parcelas cultivadas com braquiária, porém na ausência de adubação fosfatada.

Quando foi feita a calagem (Tabela 2), as maiores contagens foram obtidas na ausência de planta e de adubação (CM-celulolíticos, 12,21 x 104 UFC g- $^{-1}$ solo seco, CMC-celulolíticos, 11,45 x $10^{4} \mathrm{UFC} \mathrm{g}^{-1}$ solo seco e ureolíticos, 4,65 x $10^{4} \mathrm{UFC} \mathrm{g}^{-1}$ solo seco) ou pela aplicação de superfosfato no solo (proteolíticos, 2,52 x $10^{4} \mathrm{UFC} \mathrm{g}^{-1}$ solo seco).

Do total de isolados, observou-se maior freqüência de celulolíticos que os demais grupos estudados (Figura 1). Apenas 13 a $20 \%$ dos isolados bacterianos e $62 \%$ dos isolados fúngicos não apresentaram atividade celulolítica.. Os demais grupos 


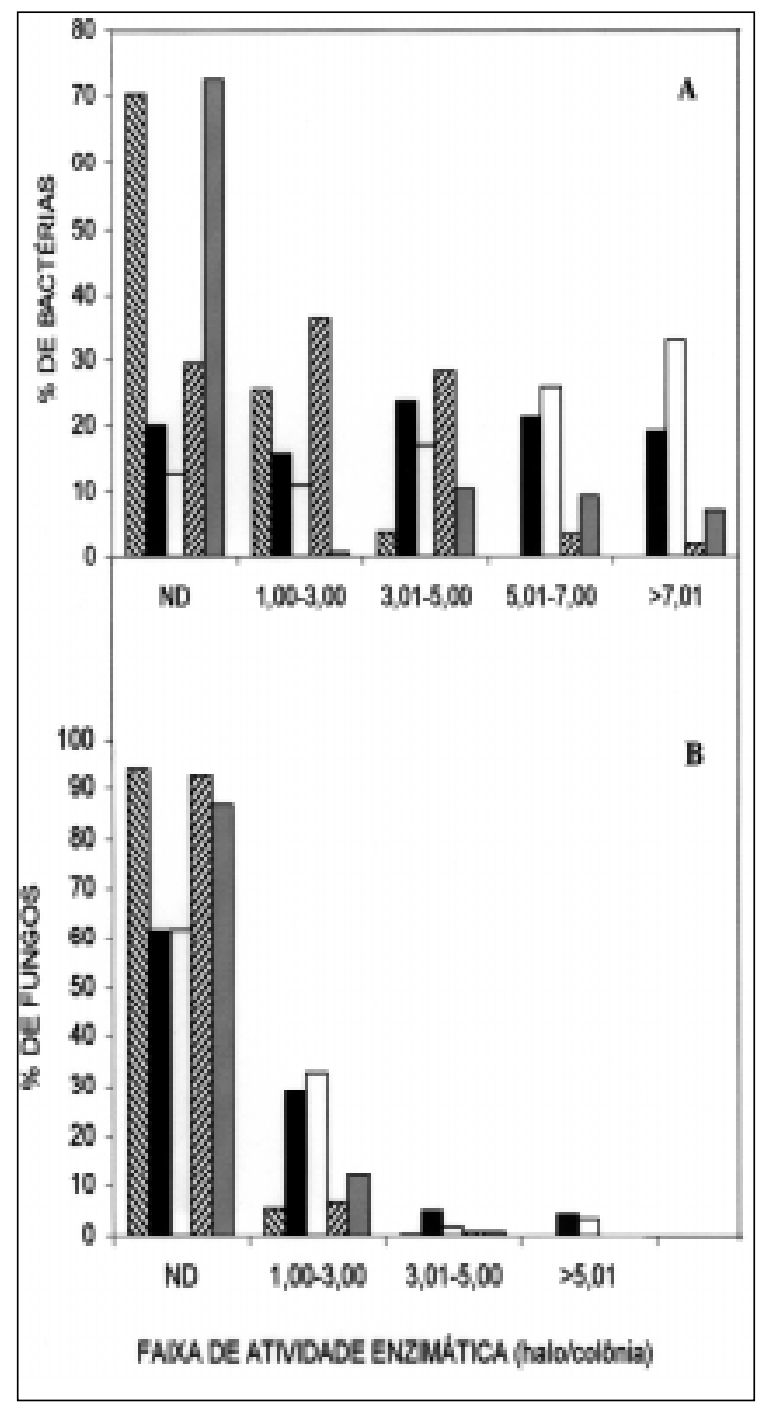

Figura 1 - Distribuição das bactérias (A) e dos fungos (B) isolados de solo por faixas de atividades. Atividades: $\mathbf{Q}$ Amilolítica, $\square$ CM-celulolítica, $\square$ CMCcelulolítica, $\square$ Proteolítica e $\square$ Ureolítica, ND Atividade Não Determinada

decresceram na seguinte ordem: bactérias celulolíticas $>$ proteolíticas $>$ amilolíticas $>$ ureolíticas e fungos celulolíticos $>$ ureolíticos $>$ proteolíticos $>$ amilolíticos.

A atividade celulolítica foi observada em todas as faixas, contudo 19 a $33 \%$ do isolados bacterianos (Figura 1A) e 3 a $4 \%$ dos isolados fúngicos (Figura 1B) apresentaram alta atividade, maior que 7,00 e 5,00 respectivamente, podendo ser considerados para trabalhos futuros. A freqüência das bactérias proteolíticas foi decrescente da faixa de menor atividade $(1,00-3,00)$, que apresentou $36,1 \%$, para a de maior atividade $(>7,00)$, com $2,0 \%$ do total. A maior parte das bactérias amilolíticas e ureolíticas não apresentou atividade, contudo as maiores porcentagens das bactérias ureolíticas foram observadas nas faixas 3,01$5,00(10,3 \%)$ e 5,01- 7,00 (7,2 \%) (Figura 1A).

A figura 1B mostra que apenas $5,6 \%$ dos fungos apresentaram atividade amilolítica, sendo a maioria $(5,2 \%)$ na faixa de menor atividade $(1,00-2,00)$. Este resultado assemelha-se ao encontrado por MELO \& CAMPOS-TAKAKI (1989) ao utilizar cepas de $\boldsymbol{A}$. niger. Resultado inesperado foi constatar maior número de isolados com atividade ureolítica $(13,1 \%)$ que amilolítica (5,6\%). Porém, confirmando os resultados obtidos neste trabalho, NANNIPIERI et al. (1979) mencionaram que tanto bactérias como fungos produzem urease, contudo as bactérias apresentaram maior atividade ureolítica. A maioria dos fungos isolados, ou seja 92,6 \% não apresentaram atividade proteolítica (Figura 1B).

Os resultados apresentados na tabela 3 mostram que as bactérias e os fungos isolados de solo apresentaram mais de uma atividade enzimática. Nas bactérias, foram verificadas até cinco atividades combinadas das enzimas ensaiadas, que possibilitariam a hidrólise de substratos orgânicos contendo várias substâncias complexas (Tabela 3). As bactérias seriam consideradas mais versáteis que os fungos por apresentarem maior número de atividades enzimáticas combinadas. Segundo ALEXANDER (1977), a baixa freqüência de microrganismos quando combinadas duas ou mais atividades enzimáticas pode estar relacionada à diversidade microbiana e metabólica, devido às diferenças estruturais entre, por exemplo, a celulose e o amido, os dois carboidratos estimulariam populações microbianas totalmente diferentes. Contudo, os resultados apresentados mostram uma ocorrência elevada de isolados com atividades enzimáticas combinadas. Entre 6,9 e 75,3 \% dos isolados bacterianos e 0,5 a $25,9 \%$ dos fungos apresentaram duas atividades combinadas (Tabela 3 ). As maiores porcentagens foram encontradas entre os isolados que apresentaram atividades combinadas CM e CMCcelulolítica. Contudo, as maiores porcentagens foram observadas nos isolados bacterianos que apresentaram atividade combinada $\mathrm{CM} \times \mathrm{CMC}$-celulolítica $\mathrm{x}$ proteolítica (57,3 \%) ou CM e CMC-celulolítica x proteolítica $\mathrm{x}$ amilolítica (18,4\%). A predominância destas enzimas pode ser justificada considerando que a celulose é um dos principais componentes da matéria orgânica vegetal incorporada ao solo (BRADY, 1974).

\section{CONCLUSÃO}

Os grupos de bactérias e fungos amilolíticos, celulolíticos, proteolíticos e ureolíticos do solo estão 
sujeitos ao efeito de culturas, da adubação fosfatada e da calagem. Tanto a freqüência como a atividade enzimática das bactérias foram maiores que dos fungos. Os isolados bacterianos também apresentaram múltiplas atividades enzimáticas.

\section{AGRADECIMENTOS}

Os autores desejam expressar seus agradecimentos à FAPESP pelo auxílio concedido e à CAPES pela concessão de bolsa à Luciana Terumi Sanomiya.

\section{REFERÊNCIAS BIBLIOGRÁFICAS}

ALEXANDER, M. Introduction to soil microbiology. New York : John Wiley, 1977. 467p.

AOKI, K. et al. Anaerobic synthesis of extracellular proteases by the soil bacterium Bacillus sp. AM-23: purification and characterization of the enzymes. Soil Biology and Biochemistry, v.27, p.1377-1382, 1995

BADALUCCO, L.; KUIKMAN, P.J.; NANNIPIERI, P. Protease and deaminase activities in wheat rhizosphere and their relation to bacterial and protozoan populations. Biology and Fertility of Soils, v.23, p.99-104, 1996.

BARROTI, G.; NAHAS, E. População microbiana total e solubilizadora de fosfato em solo submetido a diferentes sistemas de cultivo. Pesquisa Agropecuária Brasileira, Brasília, v.35, n.10, p.2043-2050, 2000

BRADY, N.C. The nature and properties of soils. New York : Macmillan, 1974. 639p.

BUNT, J.S.; ROVIRA, A.D. Microbiological studies of some subantartic soils. Journal of Soil Science, v.6, p.119-128, 1955.

BUYER, J.S.; KAUFMAN, D.D. Microbial diversity in the rhizosphere of corn grown under conventional and low-input systems. Applied Soil Ecology, v.5, p.21-27, 1996.

CAPLAN, J.A.; FAHEY, J.W. Plate-clearing technique to screen mixed microbial populations for protein degraders. Soil Biology and Biochemistry, v.14, p.373-375, 1982.

CHRISTENSEN, W.B. Urea decomposition as means of differentiatin Proteus and Paracolon cultures from each other and from Salmonella and Shigella types. Journal of Bacteriology, v.52, p.461-466, 1946.

DANTAS, M.C.; DROZDOWICZ, A. Influência dos adubos minerais na atividade celulolítica em solos de cerrados. Revista de Microbiologia, v.3, p.25-34, 1972.

DENG, S.P.; TABATABAI, M.A. Cellulase activity of soils. Soil Biology and Biochemistry, v.26, p.1347-1354, 1994

DEVLIEGHER, W.; VERSTRAETE, W. Lumbricus terrestris in a soil core experiment: nutrient-enrichment processes (NEP) and gut-associated processes (GAP) and their effect on microbial biomass and microbial activity. Soil Biology and Biochemistry, v.27, p.1573$1580,1995$.
HANKIN, L.; SANDS, D.C.; HILL, D.E. Relation of land use to some degradative enzymatic activities of soil bacteria. Soil Science, v.118, n.1, p.38-44, 1974

HENDRICKS, C.W.; DOYLE, J.D.; HUGLEY, B. A new solid medium for enumerating cellulose-utilizing bacteria in soil. Applied and Environmental Microbiology, v.61, p.2016-2019, 1995.

KUCEY, R.M.N. Phosphate-solubilizing bacteria and fungi in various cultivated and virgin Alberta soils. Canadian Journal of Soil Science, v.63, p.671-678, 1983.

LIMA, J.A.; NAHAS, E.; GOMES, A.C. Microbial populations and activities in sewage sludge and phosphate fertilizer-amended soil. Agriculture Ecosystem and Environment, v.4, p.75-82, 1996.

LINHARES, L.F.T.L.; DROZDOWICZ, A. Atividade celulolítica em alguns solos brasileiros. Revista de Microbiologia, v.3, n.2, p.91-100, 1972 .

LLOYD, A.B.; SHEAFFE, M.J. Urease activity in soils. Plant and Soil, v.39, p.71-80, 1973.

LOUW, H.A.; WEBLEY, D.M. The bacteriology of the root region of the oat plant growth under controled pot culture conditions. Journal of Applied Bacteriology, v.22, p.216-226, 1959.

MARTIN, J.P. Use of acid, rose bengal, and streptomycin in the plate method for estimating soil fungi. Soil Science, v.69, p.215232, 1950.

MELO, M.G.S.; CAMPOS-TAKAKI, G.M. Uso do meio sólido para screening de atividade amilolítica em Aspergillus niger. Arquivos de Biologia e Tecnologia, v.32, p.613-620, 1989.

NANNIPIERI, P. et al. Changes in amino acids, enzyme activities, and biomasses during soil microbial growth. Soil Science, v.127, p.26-34, 1979 .

NEAL JR, J.L.; LARSON, R.I.; ATKINSON, T.G. Changes in rhizosphere populations of selected physiological groups of bacteria related to substitution of specific pairs of chromosomes in spring wheat. Plant and Soil, v.39, p.209-212, 1973.

NISKANEN, R.; EKLUND, E. Extracellular protease-producing actinomycetes and other bacteria in cultivated soil. Journal of Agricultural Science, v.58, p.9-17, 1986.

SALAMA, A.M. et al. Effect of elevated amendments of urea on soil ureolytic activity and mycofloral count. Egyptian Journal of Microbiology, v.27, p.197-214, 1992.

SARATHCHANDRA, S.U.; UPSDELL, M.P. Nitrogen mineralisation and the activity ans populations of microflora in a high producinf yellow-brown loam under pasture. New Zealand Journal of Agricultural Research, v.24, p.171-176, 1981.

SLIZAK, W.; STEFANIAK, O. Ureolytic activity, physicochemical properties of soil and maize yield as affected by slurry. Zentralblatt fuer Mikrobiologie, v. 145, p.461-468, 1990 .

SUYAMA, K. et al. A plate count method for aerobic cellulose decomposers in soil by congo red staining. Soil Science and Plant Nutrition, v.39, n.2, p.361-365, 1993. 
TIWARI, S.C.; TIWARI, B.K.; MISHRA, R.R. Enzyme activities in soils: effects of leaching, ignition, autoclaving and fumigation. Soil Biology and Biochemistry, v.20, p.583-585, 1988.

TSHERING, R.; PAUL, A.K. Studies on protease producing microorganisms from soil sample of Darjeeling. Journal of Bengal Natural and Historical Society, v.7, p.49-58, 1988 .

VARDAVAKIS, E. Seasonal fluctuations of aerobic cellulolytic bacteria, and cellulase and respiratory activities in a soil profile under a forest. Plant and Soil, v.115, p.145-150, 1989.
WATANABE, K. Detection and identification of microorganisms in soil and natural environment. JIRCASInternational-Symposium-Series, v.5, p.71-75, 1997.

WATANABE, K.; HAYANO, K. Seasonal variation of soil protease activities and their relation to proteolytic bacteria and Bacillus spp in paddy field soil. Soil Biology and Biochemistry, v.27, p.197203, 1995.

WATANABE, K.; ASAKAWA, S.; HAYANO, K. Evaluation of extracellular protease activities of soil bacteria. Soil Biology and Biochemistry, v.26, p.479-482, 1994. 